Journal of Applied Fluid Mechanics, Vol. 9, Special Issue 2, pp. 189-195, 2016.

Selected papers from the XIIth Franco - Quebec Inter-University

Symposium on Thermal Systems -2015

Available online at www.jafmonline.net, ISSN 1735-3572, EISSN 1735-3645.

DOI: $10.36884 /$ jafm.9.SI2.25788

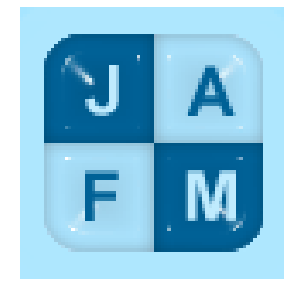

\title{
3-D Simulations of Indoor Airflow and Temperature Field with a Radiative and Convective Heater
}

\author{
C. Hemmer ${ }^{1,2}$, F. Convert ${ }^{1}$, C. Popa $^{1 \dagger}$ and G. Polidori ${ }^{1}$ \\ ${ }^{I}$ GRESPI/Thermomécanique, UFR Sciences Exactes et Naturelles, Campus du Moulin de la Housse - BP \\ 1039, 51687 Reims, France \\ ${ }^{2}$ CAMPA, rte Soissons, 51170 Fismes, France \\ †Corresponding Author Email: catalin.popa@univ-reims.fr
}

(Received October 8, 2015; accepted December 10, 2015)

\begin{abstract}
Thermal comfort in buildings is an important property for the quality of indoor environments, but also for the quantity of energy to be supplied by heating equipment. It is therefore important to understand and control the heat exchanges that come into play in the electric heaters. The electric heaters transfer their energy to the environment by convection and radiation. This paper presents a 3D numerical study of turbulent and steady airflow, in a living space (width $3.4 \mathrm{~m}, 4.5 \mathrm{~m}$ length and $2.6 \mathrm{~m}$ height). The influence of the electric heater position in the room will be reviewed to improve the thermal comfort and energy performance of the system. Transport equations of mass, momentum and energy are solved numerically using the finite volume method. Also, the radiative heat exchanges between surfaces are considered.
\end{abstract}

Keywords: Thermal comfort; Electric heater; Natural convection; Radiation; CFD.

\section{NOMENCLATURE}

$\begin{array}{ll}\text { a } & \text { absorption coefficient } \\ \mathrm{A} & \text { element surface } \\ \mathrm{Cp} & \text { specific heat capacity } \\ \mathrm{g} & \text { acceleration of gravity } \\ \mathrm{h} & \text { user height } \\ \mathrm{H} & \text { room height } \\ \mathrm{k} & \text { thermal conductivity } \\ \mathrm{l} & \text { room width } \\ \mathrm{L} & \text { room length } \\ \mathrm{n} & \text { refractive index } \\ \mathrm{P}^{*} & \text { driving pressure } \\ \overrightarrow{\mathrm{r}} & \text { position vector } \\ \overrightarrow{\mathrm{s}} & \text { direction vector } \\ \overrightarrow{\mathrm{s}^{\prime}} & \text { scattering direction vector }\end{array}$

\section{INTRODUCTION}

Thermal comfort in buildings is an important property for the quality of indoor environments, but also for the amount of energy required by the equipment's room. In addition, the energy consumption of systems is a highly watched topic in

$\begin{array}{ll}\mathrm{s} & \text { path length } \\ \mathrm{T} & \text { temperature } \\ \mathrm{u}, \mathrm{v}, \mathrm{w} & \text { velocity components } \\ \mathrm{x}, \mathrm{y}, \mathrm{z} & \text { axis coordinates } \\ \mathrm{Y} & \text { facade heater height } \\ \varsigma & \text { Stefan-Boltzmann constant } \\ \varepsilon & \text { Emissivity } \\ \Phi & \text { phase function } \\ \nu & \text { kinematic viscosity } \\ \mu & \text { dynamic viscosity } \\ \Omega & \text { solid angle } \\ \rho & \text { density, } \\ \sigma & \text { scattering coefficient } \\ \tau & \text { heater operating rate }\end{array}$

current thermal regulations. It is therefore important to understand and control the exchange of natural convection airflow coupled with radiation coming into play in domestic heating units. Several models have been developed for a better understanding in the prediction patterns of heat transfer in buildings. Some are traditional models based on energy simulations (zonal models) and others are based on 
the resolution of conservation equations (Computational Fluid Dynamics models). The zonal models based on energy simulation models are monozone or multizone. The principle is based on the division of the room volume in a limited number of zones at a constant airflow behavior, such as the plume area developing from the top of radiator or the area in contact with the floor. Very encouraging results have been obtained by Inard et al. (1995). The authors were able to show that the zonal method can give good predictions in the temperature distribution in different scenarios (electric heater, water heater and floor heating). However, Bezzo et al. (2003) note that the zonal method poses great difficulties to characterize both the flow between adjacent zones and certain mechanical quantities such as the dissipation rate of turbulent energy, which has important effects on the on physical phenomena in each area. These types of models are very useful for simulating the behavior of an annual installation and determine its consumption. However, this type of model does not have a very high precision in the spatial distribution of temperature and velocity fields in a room. Mora et al. (2002) compared the zonal method and the Computational Fluid Dynamics (CFD) method. They observed an increase of the accuracy for CFD models even if the zonal model appears to give good results. Models based on solving the conservation equations of mass, momentum and energy expensive in computation time, allow us to obtain better accuracy. The CFD method was also used in natural convection flows in a square cavity (Bhattacharya and Das 2015 and Rahmani et al. 2013). The influence of Rayleigh $10^{3}<R a<$ $10^{7}$ numbers on the hot wall of the cavity was analyzed by Bhattacharya and Das (2015). The authors have highlighted the fact that if the $\mathrm{Ra}$ number increases, so the fluid velocity and heat transfer rate increase. Rahmani et al. (2013) investigate the turbulent natural convection in a vertical enclosure, which has sinusoidal protuberances on one of its vertical walls. They showed that the local Nusselt number varies accordingly with the amplitudes of the protuberance wall. Several studies of CFD applied to the field of the building physics have already been made. These studies have shown the feasibility of the use of CFD codes to predict the thermo-aeraulic behavior on the room scale ( $\mathrm{Lu}$ et al. 1997 and Fengying et al. 2011). In these articles, one may note that the CFD method is feasible and very efficient to predict the velocity and temperature fields in a room. However, a large number of these items (Hanqing et al. 2006, Chen 2009, Sun and Wang 2010) mainly studied the influence of ventilation or air conditioning system in forced convection flow and often without taking into account the radiation. Moreover, Sevilgen and Kilic (2011) conducted a study in natural convection flow taking into account the radiation with a simplified heater (rectangular box).

This paper presents a 3D numerical study of turbulent and steady natural convection airflow coupled with radiation in a room (width $3.4 \mathrm{~m}, 4.5 \mathrm{~m}$ length and $2.6 \mathrm{~m}$ height). The influence of the electric heater position in the room will be reviewed to improve the thermal comfort and energy performance of the system.

\section{HEATER GEOMETRY}

The electric heating apparatus (Fig. 1) used for numerical simulations and experiments consists of three heating elements.

\subsection{Heater and its surroundings}

The first heating element 1 of $400 \mathrm{~W}$ delivered on the front panel consists of a heating foil to obtain on the radiator front face a homogeneous surface density flux. The heater facade is composed by a heating foil glued on a thick glass plate $(8 \mathrm{~mm})$ enameled and opaque to infrared. This glass plate 2 has an emissivity $\varepsilon=0.92$. The other two heating elementsare $300 \mathrm{~W}$ aluminum heating resistances joined together. This resistance block 3 is placed inside the electric heater. The internal resistances have an active part, concentrating power, cylindrically shaped and a diffusive part, waveshaped, to increase the exchange surface (Fig. 2a). The resistance has an emissivity between their front and rear faces of $\varepsilon=0.24$. The rest of the heater box 4 is painted. The emissivity of the paint is $\varepsilon=0.92$. The radiator has a total power rating of $1000 \mathrm{~W}$ for a height of $565 \mathrm{~mm}$, a width of $820 \mathrm{~mm}$ and a thickness of $121 \mathrm{~mm}$. We can also apply different operating rates of the heater to obtain power range between $10 \%$ and $100 \%$. The heater is placed in a room $(3.4 \mathrm{~m}$ wide, $4.5 \mathrm{~m}$ long and $2.6 \mathrm{~m}$ high). Each wall of this room can be set at a constant and uniform temperature. The emissivity of these walls is $\varepsilon=0.95$.

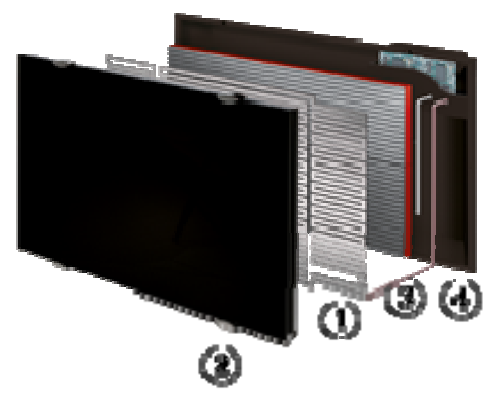

Fig. 1. Synopsis of the heater.

\subsection{Simplification of geometry}

To achieve the 3D numerical simulations, CAD files of the electric heater for the devices design were used initially. However, in these CAD files all the components constituting the heater are considered. For instance the initial mesh of the fluid domain taking into account the exact geometry of the apparatus consists of 58 million cells. For this reason, to perform numerical simulations in $3 \mathrm{D}$, a simplification of the geometry must be made to reduce the computation time.

Many mechanical (screws, hole, thermal safety, 
bracket) and electronic (cables, power board, control panel) parts of the heater are not involved in the heat transfer from the heater to the environment. For this reason; these elements are removed to simplify the geometry of the initial case (Fig. 2a). To further simplify the geometry of the heater without affecting the thermal characteristics of the device we have replaced, firstly, the standard geometry of the heating resistance by flat heating resistances (Fig. 2b) of the same height and same width $(243.0 \mathrm{~mm} \times 2.4 \mathrm{~mm})$. Secondly, the air outlet blades have been removed (Fig. 2c).

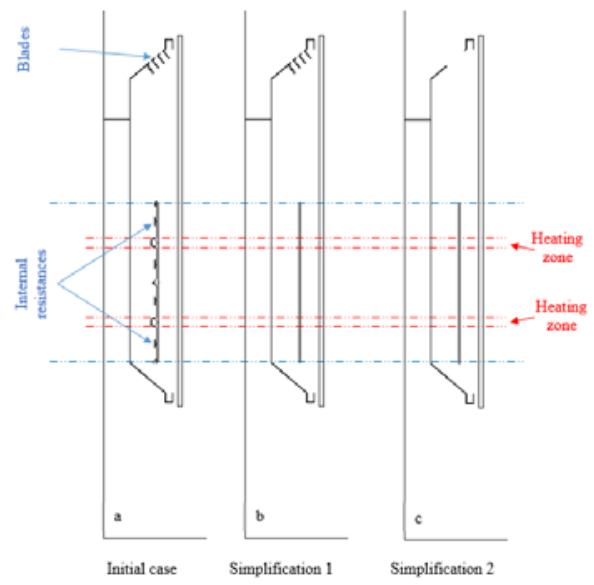

Fig. 2.Simplification steps.

In Figures 3 and 4 a comparison was made on the velocity and temperature profiles $20 \mathrm{~cm}$ above the heater, in order to determine the influence of the successive simplifications on the thermal characteristics of the device. It can be seen that these different simplifications have almost no influence $20 \mathrm{~cm}$ above the heater on the air velocities and temperatures at the outlet of the heater.
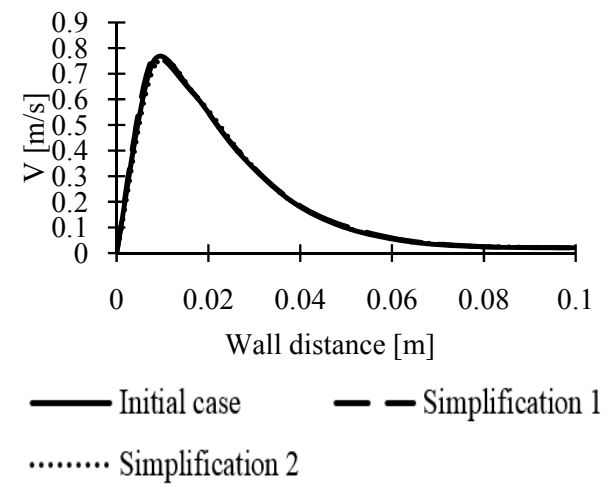

Fig. 3. Velocity profiles at $20 \mathrm{~cm}$ above the heater.

Simplifying assumptions of the air outlet and heating elements can be selected (case Simplification 2) which allowed us to reduce the mesh size to 11 million cells. The successive steps of the simplification allowed us to obtain a simplified geometry shown in Fig 5.

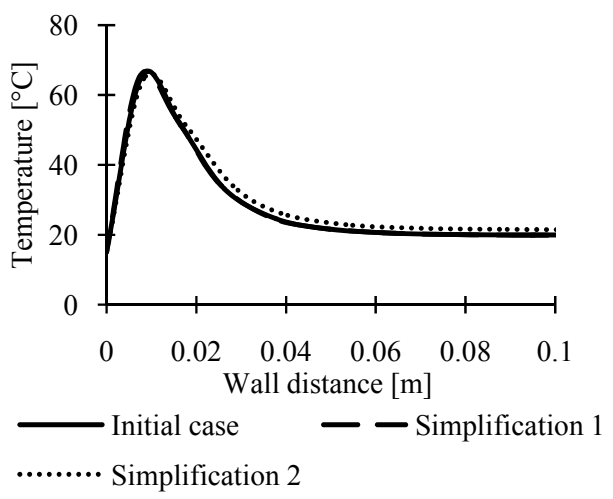

Fig. 4. Temperature profiles at $20 \mathrm{~cm}$ above the heater.
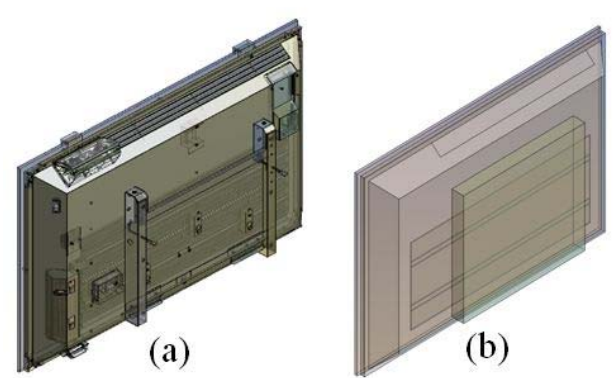

Fig. 5.Heater geometry: (a)initial and (b) simplified.

\section{METHODS}

\subsection{Physical model}

The indoor airflow physical model of natural convection coupled with radiation includes the transport equations of mass, momentum, energy and radiative transfer (Eqs $1-8$ ). The numerical simulations are carried out for a 3D steady and turbulent flow. The Reynolds-Averaged NavierStokes (RANS) equations and more specifically the $\mathrm{k}-\omega$ SST turbulence model, governs the turbulent flow. These equations are obtained by introducing the Reynolds decomposition, which consists in considering that, in turbulent flows, each instantaneous variable is the sum of a mean component and a fluctuating component. Thermophysical properties of the fluid are assumed to be dependent of the temperature because Boussinesq approximation is not valid in the considered temperature range (Gray and Giorgini 1976). The governing equations are:

Continuity equation:

$$
\frac{\partial \rho u}{\partial x}+\frac{\partial \rho v}{\partial y}+\frac{\partial \rho w}{\partial z}=\mathbf{0}
$$


$\overline{\mathrm{u}} \frac{\partial \rho \overline{\mathrm{u}}}{\partial \mathrm{x}}+\overline{\mathrm{v}} \frac{\partial \rho \overline{\mathrm{u}}}{\partial \mathrm{y}}+\overline{\mathrm{w}} \frac{\partial \rho \overline{\mathrm{u}}}{\partial \mathrm{z}}=-\frac{\partial \overline{\mathrm{P}^{*}}}{\partial \mathrm{x}}+\frac{\partial}{\partial \mathrm{x}}\left(\mu \frac{\partial \overline{\mathrm{u}}}{\partial \mathrm{x}}\right)+$

$\frac{\partial}{\partial \mathrm{y}}\left(\mu \frac{\partial \overline{\mathrm{u}}}{\partial \mathrm{y}}\right)+\frac{\partial}{\partial \mathrm{z}}\left(\mu \frac{\partial \overline{\mathrm{u}}}{\partial \mathrm{z}}\right)+\frac{\partial \overline{\mathrm{u}}}{\partial \mathrm{x}} \frac{\partial \mu}{\partial \mathrm{x}}+\frac{\partial \overline{\mathrm{v}}}{\partial \mathrm{x}} \frac{\partial \mu}{\partial \mathrm{y}}+$

$\frac{\partial \overline{\mathrm{w}}}{\partial \mathrm{x}} \frac{\partial \mu}{\partial \mathrm{z}}-\frac{\partial \rho \overline{\mathrm{u}^{\prime} \mathrm{u}^{\prime}}}{\partial \mathrm{x}}-\frac{\partial \rho \overline{\bar{u}^{\prime} \bar{v}^{\prime}}}{\partial \mathrm{y}}-\frac{\partial \rho \overline{\mathrm{u}^{\prime} \mathrm{w}^{\prime}}}{\partial \mathrm{z}}$

$\overline{\mathrm{u}} \frac{\partial \rho \overline{\mathrm{v}}}{\partial \mathrm{x}}+\overline{\mathrm{v}} \frac{\partial \rho \overline{\mathrm{v}}}{\partial \mathrm{y}}+\overline{\mathrm{w}} \frac{\partial \rho \overline{\mathrm{v}}}{\partial \mathrm{z}}=-\frac{\partial \overline{\mathrm{P}^{*}}}{\partial \mathrm{y}}+\frac{\partial}{\partial \mathrm{x}}\left(\mu \frac{\partial \overline{\mathrm{v}}}{\partial \mathrm{x}}\right)+$

$\frac{\partial}{\partial \mathrm{y}}\left(\mu \frac{\partial \overline{\mathrm{v}}}{\partial \mathrm{y}}\right)+\frac{\partial}{\partial \mathrm{z}}\left(\mu \frac{\partial \overline{\mathrm{v}}}{\partial \mathrm{z}}\right)+\frac{\partial \overline{\mathrm{u}}}{\partial \mathrm{y}} \frac{\partial \mu}{\partial \mathrm{x}}+\frac{\partial \overline{\mathrm{v}}}{\partial \mathrm{y}} \frac{\partial \mu}{\partial \mathrm{y}}+$

$\frac{\partial \overline{\mathrm{w}}}{\partial \mathrm{y}} \frac{\partial \mu}{\partial \mathrm{z}}-\frac{\partial \rho \overline{\mathrm{v}^{\prime} \mathrm{u}^{\prime}}}{\partial \mathrm{x}}-\frac{\partial \rho \overline{\mathrm{v}^{\prime} \overline{\mathrm{v}}^{\prime}}}{\partial \mathrm{y}}-\frac{\partial \rho \overline{\mathrm{v}^{\prime}} \overline{\mathrm{w}^{\prime}}}{\partial \mathrm{z}}$

$-\frac{\partial \rho \bar{w}}{\partial x}+\bar{v} \frac{\partial \rho \bar{w}}{\partial y}+\bar{w} \frac{\partial \rho \bar{w}}{\partial z}=-\frac{\partial \overline{p^{*}}}{\partial z}+\frac{\partial}{\partial x}\left(\mu \frac{\partial \bar{w}}{\partial x}\right)+$

$\frac{\partial}{\partial y}\left(\mu \frac{\partial \bar{w}}{\partial y}\right)+\frac{\partial}{\partial z}\left(\mu \frac{\partial \bar{w}}{\partial z}\right)+\frac{\partial \bar{u}}{\partial z} \frac{\partial \mu}{\partial x}+\frac{\partial \bar{v}}{\partial z} \frac{\partial \mu}{\partial y}+$

$\frac{\partial \overline{\mathrm{w}}}{\partial \mathrm{z}} \frac{\partial \mu}{\partial \mathrm{z}}-\frac{\partial \rho \overline{\mathrm{w}^{\prime} \overline{\mathrm{u}}^{\prime}}}{\partial \mathrm{x}}-\frac{\partial \rho \overline{\mathrm{w}^{\prime} \bar{v}^{\prime}}}{\partial \mathrm{y}}-\frac{\partial \rho \overline{\mathrm{w}^{\prime} \mathrm{w}^{\prime}}}{\partial \mathrm{z}}$

Energy equation

$\bar{u} \frac{\partial \rho C_{p} \bar{T}}{\partial x}+\bar{v} \frac{\partial \rho C_{p} T}{\partial y}+\bar{w} \frac{\partial \rho C_{p} T}{\partial z}=$

$\frac{\partial}{\partial \mathrm{x}}\left(\mathrm{k} \frac{\partial \overline{\mathrm{T}}}{\partial \mathrm{x}}\right)+\frac{\partial}{\partial \mathrm{y}}\left(\mathrm{k} \frac{\partial \overline{\mathrm{T}}}{\partial \mathrm{y}}\right)+\frac{\partial}{\partial \mathrm{z}}\left(\mathrm{k} \frac{\partial \overline{\mathrm{T}}}{\partial \mathrm{z}}\right)$

Radiative transfer equation for an absorbing and scattering medium emissivity at a position $\vec{r}$ in the direction $\vec{s}$ is:

$$
\begin{aligned}
& \frac{\mathrm{dI}(\overrightarrow{\mathrm{r}}, \overrightarrow{\mathrm{s}})}{\mathrm{ds}}+(\mathrm{a}+\sigma) \mathrm{I}(\overrightarrow{\mathrm{r}}, \overrightarrow{\mathrm{s}})= \\
& \operatorname{an}^{2} \frac{\varsigma \mathrm{T}^{4}}{\pi}+\frac{\sigma}{4 \pi} \int_{0}^{\pi} \mathrm{I}\left(\overrightarrow{\mathrm{r}}, \overrightarrow{\mathrm{s}}^{\prime}\right) \Phi\left(\overrightarrow{\mathrm{s}} . \overrightarrow{\mathrm{s}}^{\prime}\right) \mathrm{d} \Omega
\end{aligned}
$$

The $\mathrm{k}-\omega$ SST turbulence model (Menter2009) is a two-equation eddy-viscosity model that combines $k-\omega$ formulation in the inner parts of the boundary layer and $k-\varepsilon$ formulation in the free-stream. Two additional transport equations for the turbulence kinetic energy per unit mass $(\mathrm{k})$ and the specific dissipation rate $(\omega)$ are solved. These equations are:

$$
\begin{aligned}
& \frac{\partial}{\partial x_{j}}\left(\rho k \overline{U_{j}}\right)=\frac{\partial}{\partial x_{j}}\left(\Gamma_{k} \frac{\partial k}{\partial x_{j}}\right)+G_{k}-Y_{k} \\
& \frac{\partial}{\partial x_{j}}\left(\rho \omega \overline{U_{j}}\right)=\frac{\partial}{\partial x_{j}}\left(\Gamma_{\omega} \frac{\partial \omega}{\partial x_{j}}\right)+G_{\omega}-Y_{\omega}+D_{\omega}
\end{aligned}
$$

where $Y_{k}, Y_{\omega}$ are the turbulent dissipationsof $\mathrm{k}$ and $\omega$, respectively $\Gamma_{k}, \Gamma_{\omega}$ are the effective diffusivities of $\mathrm{k}$ and $\omega$, respectively; $G_{k}, G_{\omega}$ correspond to the generation of turbulence of $\mathrm{k}$ and $\omega$, respectively due to the mean velocity gradients and $D_{\omega}$ is the cross-diffusion term.

\subsection{Numerical method}

Transport equations of mass, momentum, energy radiative transfer and turbulence (Eqs $1-8)$ are solved numerically using the finite volume method (Patankar). This method is based on the spatial integration of transport equations relative to control volumes. The coupling between velocity and pressure is achieved with the algorithm "Coupled Scheme" that solves the equations of continuity and momentum simultaneously and gives an advantage to treat flows with a strong interdependence between dynamic and thermal fields. Numerical simulations are performed with ANSYS Fluent ${ }^{\circledR}$ CFD commercial software. In this numerical study the Central-Differenced Scheme was used for the spatial discretization for diffusive term, the SecondOrder Upwind Scheme for the convective term and the Body Force Weighted Scheme for the continuity equation. The convergence criteria were based on the residuals resulting from the integration of the conservation equations over finite control volumes. During the iterative calculation process, these residuals were constantly monitored and carefully scrutinized. For all simulations performed in this study, converged solutions were achieved with residuals as low as $10^{-4}$ (or less) for all the governing equations.

\subsection{Validation}

Fig 6 shows a comparison between the numerical and experimental temperatures obtained by infrared thermography on the front of the heater. Thermal validation of the physical model and the mesh were conducted with the different electric powers of the heater $(100,500$ and $1000 \mathrm{~W})$ corresponding to the operating rate $\tau=10,50$ and $100 \%$. Whatever the operation rate used for the heater, it may be noted that the maximum deviation on the temperature facade between the numerical results and those obtained by the infrared thermography is $6 \%$.

Fig 7 and 8 present a comparison between the velocity profiles experimentally obtained using the PIV method (Particle Image Velocimetry) and numerical results in a plane which is located $10 \mathrm{~cm}$ above the radiator, for two operating rate $(\tau=20$ and $80 \%$ ). Comparing these results, it is found that the experimental shape of velocity profiles is similar to that of numerical simulations, whatever the operation rate of the device $(20$ and $80 \%)$. However, a $13 \%$ gap was observed for the maximum velocity and a $5 \%$ one for the volume flow rate of the thermal plume, $10 \mathrm{~cm}$ above the radiator.

These differences on the maximum velocities between numerical simulation and experimental study can be explained by the use in the PIV method of an algorithm based on a spatial average (interpolation window) and of a temporal mean (200 doublets of images at $3 \mathrm{~Hz}$ ) for calculating the velocity. So if the plume changes its position in time, we obtain a lower peak velocity amplitude but wider. 


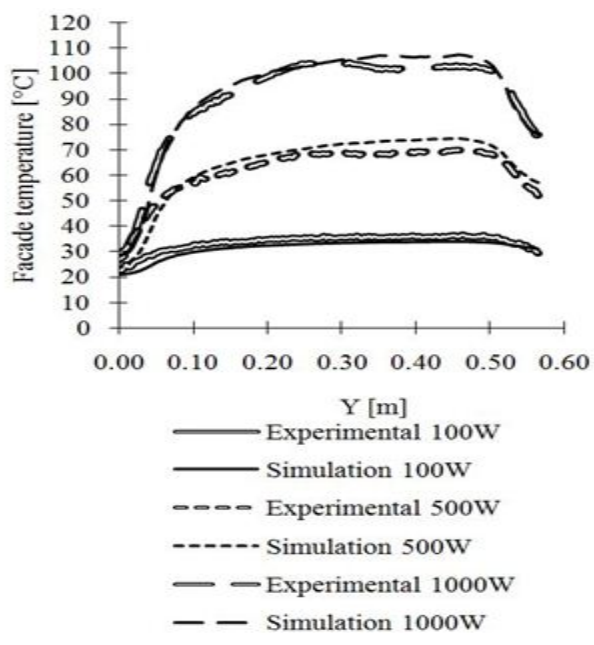

Fig. 6.Vertical temperature profile at front façade.

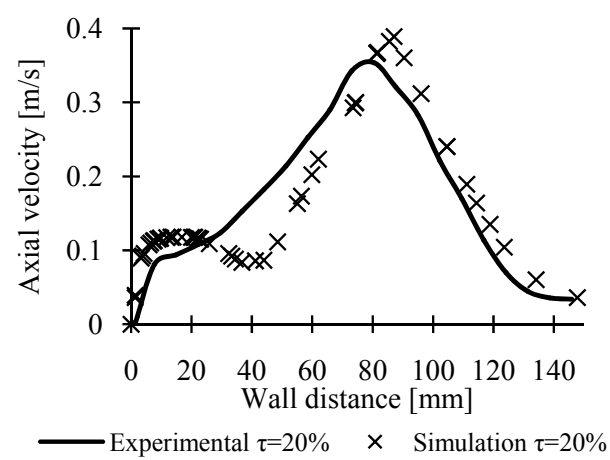

Fig. 7. Velocity profile at $10 \mathrm{~cm}$ on top of the heater for $\tau=\mathbf{2 0} \%$.

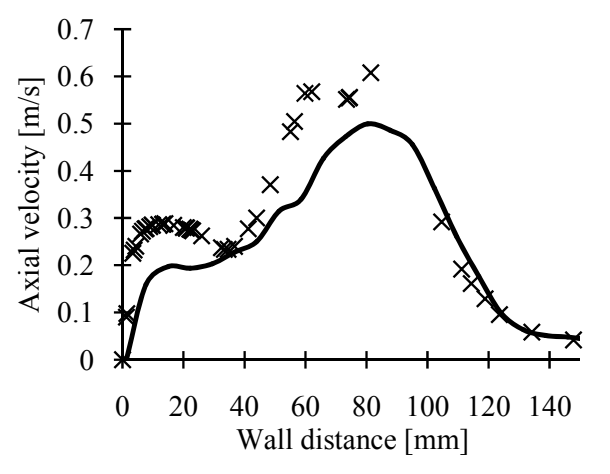

Experimental $\tau=80 \% \quad \times \quad$ Simulation $\tau=80 \%$

Fig. 8. Velocity profile at $10 \mathrm{~cm}$ on top of the heater for $\tau=\mathbf{8 0} \%$

\section{RESULTS}

In this paper, a 3D numerical study of indoor airflow and temperature field with a radiative and convective heater was achieved. The study focuses on the influence of the heater position in the room, nominal power $1000 \mathrm{~W}$. In the first studied case (Case 1), the heater is installed on a cold wall (outdoor type) maintained at $15{ }^{\circ} \mathrm{C}$ while the opposed walls are maintained at $19{ }^{\circ} \mathrm{C}$ (inner wall type). In the second case (Case 2) the heater is installed on an inner wall type $\left(19^{\circ} \mathrm{C}\right)$ while the opposite wall is of outdoor type $\left(15^{\circ} \mathrm{C}\right)$. The other walls of the room remain at $19^{\circ} \mathrm{C}$ (inner wall type).

In fig 9 one can observe the streamlines and velocity field in the central plane of the room when the operation rate for the heater is $40 \%$. First of all, it can be noted at the electric heater outlet, that the airflow approaches the adjacent wall. Approaching the ceiling, indoor airflow is dispersed along the vertical wall. Small vortices, are also formed along the edge wall / ceiling. Finally, indoor air becomes stratified and feeds the plume that exits the electric heater. Similar phenomena are observed for different heater operation rates.

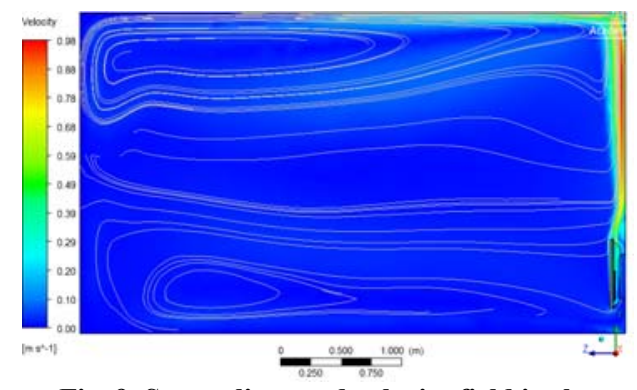

Fig. 9. Streamlines and velocity field in the middle plane of the room $(\tau=40 \%)$.

To highlight the critical points of the device during use to different operation rates $(\tau=20,40,60,80$ and $100 \%$ ), temperatures and air velocities have been observed (Table 1). Indeed, each element has a critical temperature that must not be exceeded. The heating foil consists of plastic polymer layers which may not exceed a temperature of $120^{\circ} \mathrm{C}$ to prevent its melting. Accessible parts of the heater by the user, normally the facade, the box and the air outlet must not exceed a maximum temperature of $110^{\circ} \mathrm{C}$ to prevent accidental burn. In addition, for indoor air quality reasons, the internal electrical resistances shall not exceed a maximum temperature of $250{ }^{\circ} \mathrm{C}$ to not dry out the air and dust carbonize. Regardless of the operation rate, it can be observed that the maximum temperatures of the heating elements and air output never exceed the critical threshold. However, the average temperature in the room, guaranteeing a comfort degree decreases only by $0.5 \%$ to an operating rate of $80 \%$.

Table 1 Indoors physical parameters

\begin{tabular}{|c|c|c|c|c|c|}
\hline $\boldsymbol{\tau}$ & $20 \%$ & $40 \%$ & $60 \%$ & $80 \%$ & $100 \%$ \\
\hline $\mathrm{T}_{\max }$ Facade $\left({ }^{\circ} \mathrm{C}\right)$ & 54.7 & 56.4 & 68 & 86 & 100 \\
\hline $\begin{array}{c}\mathrm{T}_{\max } \text { Heating } \\
\text { Foil }\left({ }^{\circ} \mathrm{C}\right)\end{array}$ & 56 & 59.4 & 73 & 92.5 & 108 \\
\hline $\begin{array}{c}\mathrm{T}_{\max } \text { Resistance } \\
\left({ }^{\circ} \mathrm{C}\right)\end{array}$ & 90 & 123.6 & 161 & 197 & 228 \\
\hline $\mathrm{T}_{\max }$ Outlet $\left({ }^{\circ} \mathrm{C}\right)$ & 46 & 58.6 & 68 & 79 & 92.3 \\
\hline $\mathrm{T}_{\mathrm{av}}$ Room $\left({ }^{\circ} \mathrm{C}\right)$ & 19 & 19.4 & 19.7 & 20 & 20.1 \\
\hline $\mathrm{V}_{\max }(\mathrm{m} / \mathrm{s})$ & 0,72 & 0,914 & 0,98 & 1,17 & 1,20 \\
\hline
\end{tabular}


In Fig 10 and 11, the thermal fields are shown in the room center in the perpendicular plane to the radiator, for different configurations studied (cases 1 and 2). Whatever the position of the heater, one can observe a stratification phenomenon in the room. Outgoing warm air through the outlet heater rises along the wall. This is due to its lower density. The warm airflow follows the ceiling and then descends again along the opposite wall. It can be seen that in case 2, the hot air down lower in the vicinity of the opposite wall unlike the case 1 . Finally, the air stratified in the room according to its temperature and feeds the plume outgoing the radiator.

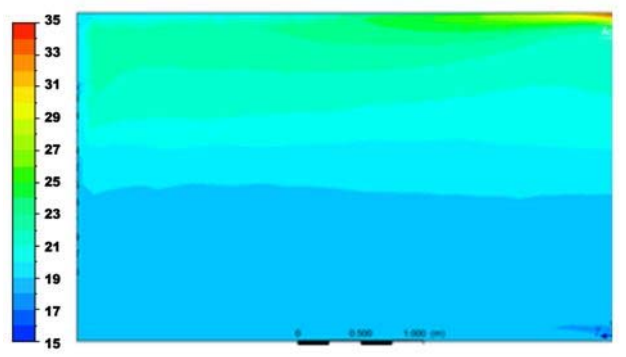

Fig. 10. Thermal field in the middle plane of the room (Case 1)

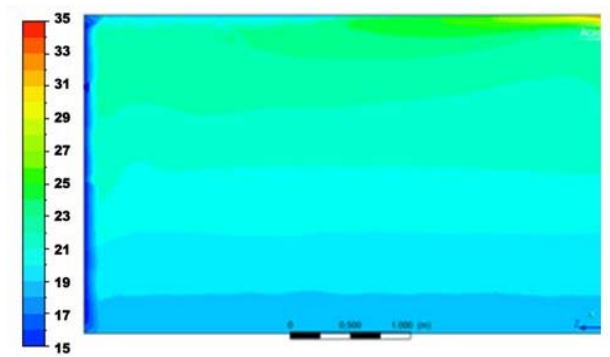

Fig. 11. Thermal field in the middle plane of the room (Case 2).

To compare the two cases based on thermal comfort, we will create an arbitrary parameter called average temperature determined in a sphere of $1.25 \mathrm{~m}$ diameters. In order to link the average temperature to the user comfort the sphere is located at $1 \mathrm{~m}$ heights. In addition, this sphere was positioned at $2 \mathrm{~m}$ of the heater to the room inside. The sphere position may be representative of the average position of the human body in the room. It is noted that the average temperature increased by one degree $\left(22.3{ }^{\circ} \mathrm{C}\right.$ to $\left.23.1{ }^{\circ} \mathrm{C}\right)$ when, instead of installing the heater on an outdoor wall (maintained at $15{ }^{\circ} \mathrm{C}$ ) it is installed on the interior wall (maintained at $19^{\circ} \mathrm{C}$ ).

Fig 12, 13 and 14 show the vertical temperature profiles obtained for cases 1 and 2, in the middle of the width of the room and at different distances from the radiator $(1,3$ and $4 \mathrm{~m})$. There is a thermal gradient in both cases between the floor and the ceiling of the room of about $6^{\circ} \mathrm{C}$.

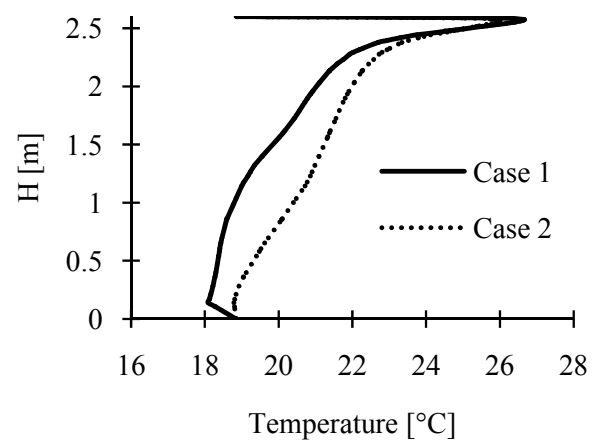

Fig. 12. Vertical temperature profileat $1 \mathrm{~m}$ in front of the heater.

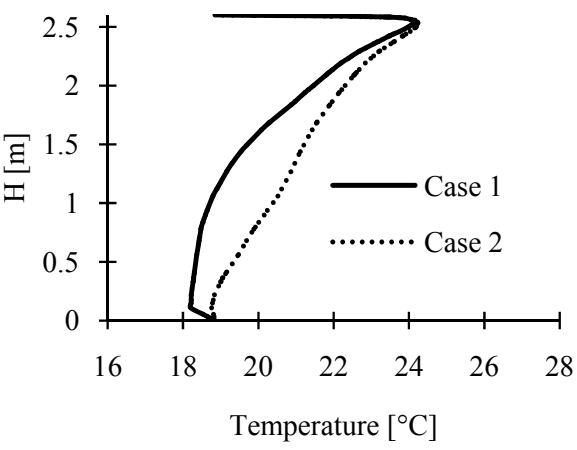

Fig. 13. Vertical temperature profileat $3 \mathrm{~m}$ in front of the heater.

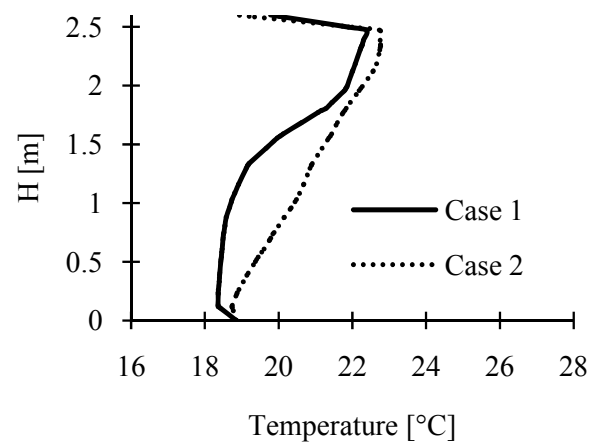

Fig. 14. Vertical temperature profileat $4 \mathrm{~m}$ in front of the heater

\section{CONCLUSION}

A 3D numerical study of turbulent and steady natural convection airflow coupled with radiation in a room was conducted. Two heating configurations were analyzed: first the electric heater is positioned on the cold wall, and then the device is positioned on the wall opposite to the cold wall. The numerical model used in the case of a heater in a room gives reliable results for experiments. The numerical results have shown that if the heater is positioned in front of the cold wall average temperature felt in the center of the room by the user is greater than $1{ }^{\circ} \mathrm{C}$ 
compared to the case where the device is attached to the cold wall. Moreover, in this configuration, the vertical thermal gradient is linear up to $2.3 \mathrm{~m}$ whatever considered axis in middle plane of the room. In conclusion, the heater positioned opposite the outer wall provides better heat distribution within the room and thus better thermal comfort for the user.

\section{ACKNOWLEDGEMENTS}

This work is financially supported by the European Union (EU) through the European Regional Development Fund (FEDER), the ChampagneArdenne region and the company CAMPA as part of Effi-SiEMCE project.

\section{REFERENCES}

Bezzo, F., S. Macchietto, and C. C. Pantelides, (2003). A general methodology for hybrid multizonal and CFD models: Part I Theoretical framework. Computers \& Chemical Engineering, 501-511.

Bhattacharya P. and S. Das (2015).A Study on Steady Natural Convective Heat Transfer inside a Square Cavity for Different Values of Rayleigh and Nusselt Numbers.Journal of Applied Fluid Mechanics 8 (3), 635- 640.

Chen, Q. (2009). Ventilation performance prediction for buildings : A method overview and recent applications.Building and Environment, 44(4), 848-858.

Fengying, Y., L., Huaigang W. Long andZ. Haixia (2011). Simulation of indoor dynamic thermal comfort based on CFD.Proceedings - 4th International Conference on Intelligent Computation Technology and Automation, (ICICTA 2011) 2, 5751027, pp. 860-865.

Gray, D. D., A. Giorgini, (1976). The validity of the Boussinesq approximation for liquids and gases. International Journal of Heat and Mass Transfer 19(5), 545-551.

Hanqing, W., H., Chunhua, L., Zhiqiang, T. G.,
Yingyun, L., Zhiyong, W. (2006). Dynamic evaluation of thermal comfort environment of air conditioned buildings.Building and Environment, 41(11), 1522-1529.

Inard, C., H. Bouia, and P. Dalicieux, (1995).Prediction of air temperature distribution in buildings with a zonal model.Energie and Buildings 24, 125-132.

Lu, W., A. T. Howarth., and A. P. Jeary (1997).Prediction of airflow and temperature field in a room with convective heat source.Building and Environment 32, 541-550.

Menter, Florian R. (2009) Review of the shearstress transport turbulence model experience from an industrial perspective. International Journal of Computational Fluid Dynamics. 23, 305-316.

Mora, L., A. J., Gadgil, E. Wurtz, and C. Inard, (2002). Comparing zonal and CFD model predictions of indoor airflows under mixed convection conditions to experimental data.Proceeding of the EPIC'02 Conference, Lyon, France, pp. 735-740. Lyon University.

Patankar, S. V., (1980). Numerical heat transfer and fluid flow, Hemisphere Publishing Corporation, Mc. Graw Hill Book Company.

Rahmani, K., A. Bentebbiche, B. Draoui, (2013). Numerical investigation of turbulent natural convection for a cavity having sinusoidal protuberances on a vertical wall. Journal of Applied Fluid Mechanics 6 (4), 491-499.

Sevilgen, G., M. Kilic, (2011). Numerical analysis of air flow, heat transfer, moisture transport and thermal comfort in a room heated by two-panel radiators. Energy and Buildings, 43(1), 137146.

Sun, Z., S. Wang, (2010).A CFD-based test method for control of indoor environment and space ventilation.Buiding and Environment 45(6), 1441-1447. 